\title{
El potencial redistributivo de la fiscalidad en América Latina
}

\author{
Michael Hanni, Ricardo Martner y Andrea Podestá
}

RESUMEN

En este trabajo se efectúan mediciones, comparables con las metodologías internacionales, sobre la incidencia distributiva del impuesto a la renta y las transferencias públicas monetarias en 17 países de América Latina. Los resultados indican que la política fiscal juega un papel limitado en mejorar la distribución del ingreso disponible; el coeficiente de Gini baja apenas tres puntos porcentuales luego de la acción fiscal directa. En promedio, el $61 \%$ de esta reducción proviene de las transferencias públicas en efectivo y el resto de los tributos directos, reflejo del imperativo de fortalecer el impuesto a la renta personal. Las mediciones de encuestas de hogares permiten simular los efectos potenciales de reformas tributarias orientadas a aumentar las tasas medias efectivas del decil superior. Si esta recaudación adicional se destina a transferencias focalizadas, los efectos son muy significativos. En consecuencia, es necesario evaluar las reformas tributarias considerando el uso de estos recursos.

PALABRAS CLAVE

CLASIFICACIÓN JEL

AUTORES
Tributación, impuesto a la renta, ingresos, distribución del ingreso, medición, datos estadísticos, política fiscal, América Latina

H22, H23, H24, H5, H55

Michael Hanni es oficial asociado de Asuntos Económicos de la División de Desarrollo Económico de la CEPAL.michael.hanni@cepal.org

Ricardo Martner es jefe de la Unidad de Asuntos Fiscales de la División de Desarrollo Económico de la CEPAL. ricardo.martner@cepal.org

Andrea Podestá es consultora de la División de Desarrollo Económico de la cEPAL. andrea.podesta@cepal.org 


\section{I}

\section{Introducción}

Si bien la desigualdad de los países de América Latina es un hecho ampliamente conocido, las políticas públicas, y especialmente las fiscales, no se han orientado a este objetivo con la fuerza requerida. En CEPAL (2008) se resalta que el gasto social tiene repercusiones muy importantes en los estratos de menores ingresos, pero no así en las mediciones de la desigualdad. Sobre esta última, los cambios positivos registrados en la última década provienen principalmente de una mejor distribución de los ingresos laborales, pero en bastante menor medida del papel redistributivo del Estado.

A pesar de las dificultades metodológicas y de la poca confiabilidad de los datos disponibles, existe en la región una tradición de estudios de incidencia de la política fiscal que data de hace por lo menos tres décadas (véase Gómez Sabaini y Morán, 2013). Durante el primer decenio del siglo XXI se realizaron una serie de estudios sobre la incidencia de la política fiscal en los países centroamericanos, andinos y otros países de América del Sur ${ }^{1}$. Entre los resultados se destaca que el impuesto sobre el valor agregado (IVA) tiene un efecto redistributivo modesto aunque regresivo y que el impuesto a la renta personal presenta una muy alta progresividad, pero un muy moderado efecto redistributivo, sobre todo si se lo compara con la capacidad redistributiva del gasto público social. Allí se concluye que la política fiscal, en su conjunto, no juega un papel redistributivo relevante.

Más recientemente se han publicado varios trabajos en los que se evalúa la incidencia de gastos e impuestos en la desigualdad y la pobreza en siete países de la región: Argentina, Bolivia (Estado Plurinacional

Este documento es un resumen del Primer informe del Proyecto del Contrato de Servicios CEPAL/FIIAPP en el marco del programa EUROSocial II, componente IV: "Recientes reformas tributarias y de gasto público en América Latina: efectos distributivos". Los autores agradecen la colaboración de Rodrigo Astorga e Ivonne González, así como el permanente apoyo de Xavier Mancero en el análisis de las encuestas de hogares y los comentarios y sugerencias de Juan Pablo Jiménez, Michel Jorrat y de un árbitro anónimo.

${ }^{1}$ Estos estudios incluyen a los siguientes países: Bolivia, Colombia, Ecuador, Perú, Venezuela (República Bolivariana de), Costa Rica, El Salvador, Guatemala, Honduras, Nicaragua, Panamá, República Dominicana, Brasil, Chile, Paraguay y Uruguay. Véase la Serie de Equidad Fiscal del Banco Interamericano de Desarrollo (BID): Barreix, Roca y Villela (2006); Barreix, Bes y Roca (2009), y Jorrat (2010). de), Brasil, México, Paraguay, Perú y Uruguay² ${ }^{2}$ En estas investigaciones se estima el efecto de los tributos directos e indirectos, de los subsidios indirectos y de las transferencias en efectivo y en especie a partir de encuestas de hogares.

En el marco de un proyecto del Programa de las Naciones Unidas para el Desarrollo (PNUD) y el Centro Internacional de Investigaciones para el Desarrollo de Canadá (CIID), se desarrollaron modelos de microsimulación (con y sin cambios de comportamiento) para cinco países latinoamericanos (Brasil, Chile, Guatemala, México y Uruguay) con el objetivo de estudiar la repercusión en la distribución del ingreso o la pobreza de modificaciones en los impuestos directos, en los indirectos o en los beneficios sociales (Urzúa, 2012).

Por su parte, la Organización para la Cooperación y el Desarrollo Económicos (OCDE) ha publicado una serie de estudios para sus países miembros. Joumard, Pisu y Bloch (2012) señalan que el impacto redistributivo de los impuestos y transferencias depende del tamaño, la estructura y la progresividad de cada componente, y encuentran que los impuestos y las transferencias monetarias reducían la desigualdad del ingreso, medida según el coeficiente de Gini, en un $25 \%$ en promedio para los países miembros de la oCDE a finales del decenio de 2000. En estos países, las transferencias directas disminuyen más la dispersión del ingreso que los impuestos: tres cuartos de la reducción en la desigualdad entre el ingreso de mercado y el ingreso disponible pueden atribuirse a las transferencias, y el resto a los impuestos. Además, los países con una distribución más desigual de los ingresos de mercado tienden a redistribuir más.

Con estos antecedentes, el primer objetivo de este trabajo es estimar la incidencia del impuesto sobre la renta y de las transferencias monetarias públicas en la distribución del ingreso disponible, respecto de un grupo amplio de 17 países de América Latina, de manera de difundir mediciones comparables con las metodologías internacionales. Un segundo objetivo es simular los eventuales efectos de reformas potenciales de los sistemas impositivos, con el fin de demostrar que

\footnotetext{
2 Véase Lustig, Pessino y Scott (2013), y Higgins y otros (2013).
} 
los instrumentos tributarios - y sobre todo el buen uso del aumento derivado en la recaudación-sí pueden tener impactos significativos en la distribución del ingreso disponible.

El presente documento se organiza de la siguiente forma. En la sección II se expone brevemente la metodología utilizada para medir la incidencia de la política fiscal. A continuación, en la sección III, se analizan los resultados obtenidos tanto para las transferencias públicas en efectivo como para el impuesto sobre la renta personal. En la sección IV se examinan los efectos redistributivos de las transferencias directas según grupos poblacionales. Luego, la sección $\mathrm{V}$ se focaliza en la evaluación del efecto del impuesto sobre la renta personal en la progresividad y la redistribución del ingreso disponible. En seguida, en la sección VI se simulan y evalúan los efectos de ciertos cambios en este tipo de impuesto. Por último, la sección VII contiene algunas reflexiones en torno de las reformas requeridas para mejorar la acción fiscal en su conjunto.

\section{II}

\section{Métodos de estimación de la incidencia de la acción fiscal}

Al igual que en los estudios disponibles en la región, la metodología consiste en aplicar un análisis de incidencia estándar para evaluar la progresividad o regresividad de la política fiscal y su efecto en la redistribución del ingreso. Este tipo de análisis estático no tiene en cuenta efectos de comportamiento (por ejemplo, en la oferta de trabajo y en las estrategias de evasión o elusión de los contribuyentes), del ciclo de vida ni de equilibrio general. Por lo tanto, no se consideran en él las funciones de reacción de los agentes económicos ante la introducción o modificación de los impuestos y las transferencias.

A grandes rasgos, en estas investigaciones se comparan la distribución del ingreso antes y después del pago de impuestos o de las transferencias públicas, o de ambas, y así se evalúa si los sistemas tributarios, las transferencias o la política fiscal en su conjunto cumplen con su papel redistributivo.

La fuente de información utilizada es la última encuesta disponible en cada país respecto de los ingresos y gastos de los hogares. No obstante, un problema conocido de los datos de ingresos provenientes de las encuestas de hogares es que estos aparecen subestimados debido a diversos factores, como por ejemplo, las encuestas suelen no captar a los individuos de muy altos ingresos, la falta de respuesta parcial o total y la subdeclaración de ingresos (especialmente en la parte alta de la distribución del ingreso).

En general, dado que en las encuestas de hogares habitualmente hay casos de subdeclaración o no respuesta, los datos de ingreso han sido corregidos por la División de Estadísticas y Proyecciones Económicas de la CEPAL. Así, en la corrección en casos de no respuesta de ingresos, se imputa a cada persona la renta promedio declarada por individuos similares; en tanto que el ajuste por subdeclaración consiste en multiplicar los ingresos de cada fuente por un factor igual a la discrepancia con el correspondiente ingreso per cápita indicado en las cuentas nacionales ${ }^{3}$. Esta práctica eleva los ingresos medios y también suele modificar su distribución. En particular, se tiende a aumentar la desigualdad, sobre todo porque la brecha en los ingresos de capital se imputa exclusivamente al quintil más rico (CEPAL, 2012c) ${ }^{4}$.

Sin embargo, el ajuste por subdeclaración no está exento de inconvenientes y la disponibilidad y calidad de la información proveniente de cuentas nacionales varían entre países y períodos bajo estudio. Además, los países introducen modificaciones al proceso de construcción de las cuentas nacionales, ya sea en el año base de las series o en el marco metodológico. Estas modificaciones, distintas entre países, sin duda constituyen un mejoramiento en el sistema de cuentas, pero afectan a la estimación de los ingresos y gastos de los hogares en la medida que varían algunas fuentes de información, cobertura de conceptos, ponderaciones entre sectores y actividades de la economía; y además, cada nuevo esquema metodológico no representa solo un simple reordenamiento de su predecesor, sino que modifica el tratamiento de ciertas partidas, incorpora

\footnotetext{
${ }^{3}$ Para más detalles véase el trabajo pionero de Altimir (1987).

${ }^{4}$ No fue posible el ajuste por subdeclaración de los ingresos en los siguientes países: Colombia, El Salvador, Honduras, Nicaragua y Uruguay.
} 
nuevas categorías y elimina algunas clasificaciones usadas previamente (CEPAL, 2012a) ${ }^{5}$.

Es importante realizar algunas precisiones metodológicas. La unidad de análisis es el hogar y

5 Actualmente, la CEPAL se encuentra en un proceso de revisión de la metodología de ajuste de los ingresos a cuentas nacionales con el fin de mejorar la consistencia de estos y la comparabilidad de los resultados entre países y a lo largo del tiempo. se considera como indicador de bienestar al ingreso per cápita equivalente; la definición de ingresos es la propuesta por la OCDE (2008) para que los resultados sean comparables entre países. Se efectúan ciertos supuestos respecto del pago de los impuestos, ya que se asume que el impuesto a la renta personal es soportado por la persona física gravada y que los trabajadores afrontan completamente las contribuciones a la seguridad social, aunque solo se paga impuestos en los sectores formales de la economía.

\begin{tabular}{|c|}
\hline $\begin{array}{c}\text { RECUADRO } 1 \\
\text { INDICADORES DE PROGRESIVIDAD Y REDISTRIBUCIÓN }\end{array}$ \\
\hline $\begin{array}{l}\text { La progresividad del impuesto sobre la renta se evalúa según la participación de cada decil en la recaudación, } \\
\text { la progresión de tasas medias y el índice de Kakwani. } \\
\text { La progresión de tasas medias indica el pago del impuesto que hace cada decil, expresado como } \\
\text { porcentaje de su ingreso (tasa efectiva del impuesto). Un impuesto es progresivo cuando a mayor ingreso, } \\
\text { mayor es la proporción que se paga. } \\
\text { El índice de Kakwani compara la curva de Lorenz del ingreso antes de impuestos con la curva de } \\
\text { concentración del impuesto, es decir: }\end{array}$ \\
\hline $\mathrm{K}=$ cuasi Gini (impuesto) - Gini (ingreso antes de impuestos) \\
\hline $\begin{array}{l}\text { Si K es mayor (menor) que cero, el impuesto es progresivo (regresivo) y la desigualdad disminuye } \\
\text { (aumenta). } \\
\text { El índice de Reynolds-Smolensky es un indicador de la capacidad redistributiva del tributo: } \\
\text { RS = Gini (ingreso antes impuestos) - Gini (ingreso después de impuestos) }\end{array}$ \\
\hline $\begin{array}{l}\text { Si RS es mayor (menor) que cero, su valor indica la contribución del impuesto a reducir (incrementar) } \\
\text { la desigualdad. } \\
\text { Para capturar el efecto de reordenación, es decir, para evaluar si se preserva el ordenamiento de } \\
\text { de los individuos según su nivel de ingresos luego del pago de los impuestos, se recurre al índice de } \\
\text { Atkinson-Plotnick: }\end{array}$ \\
\hline$A-P=G(Y)-C X(Y)$ \\
\hline $\begin{array}{l}\text { donde } \mathrm{G}(\mathrm{Y}) \text { : Gini del ingreso después de impuestos y } \mathrm{CX}(\mathrm{Y}) \text { : Gini del ingreso después de impuestos, pero con } \\
\text { el ordenamiento de individuos antes de impuestos. Si el índice es cero, significa que no hubo reordenamiento } \\
\text { y si es } 1 \text {, se ha invertido totalmente el ordenamiento. }\end{array}$ \\
\hline Fuente \\
\hline
\end{tabular}

\section{III}

\section{Resultados para 17 países de América Latina}

Es importante iniciar el análisis considerando un rasgo distintivo de la desigualdad en la región: la elevada fracción del ingreso que capta el estrato más alto, es decir, el 10\% de los hogares más ricos (véase el gráfico 1). En promedio, este grupo concentra un
$32 \%$ de los ingresos totales, aunque la dispersión entre países se mueve en 10 puntos porcentuales hacia arriba de ese valor: Brasil, Chile, Guatemala, Honduras y Paraguay, o hacia abajo: Uruguay y Venezuela (República Bolivariana de). 
América Latina (18 países): participación en el ingreso por grupos de deciles, alrededor de $2012^{a}$

(En porcentajes)

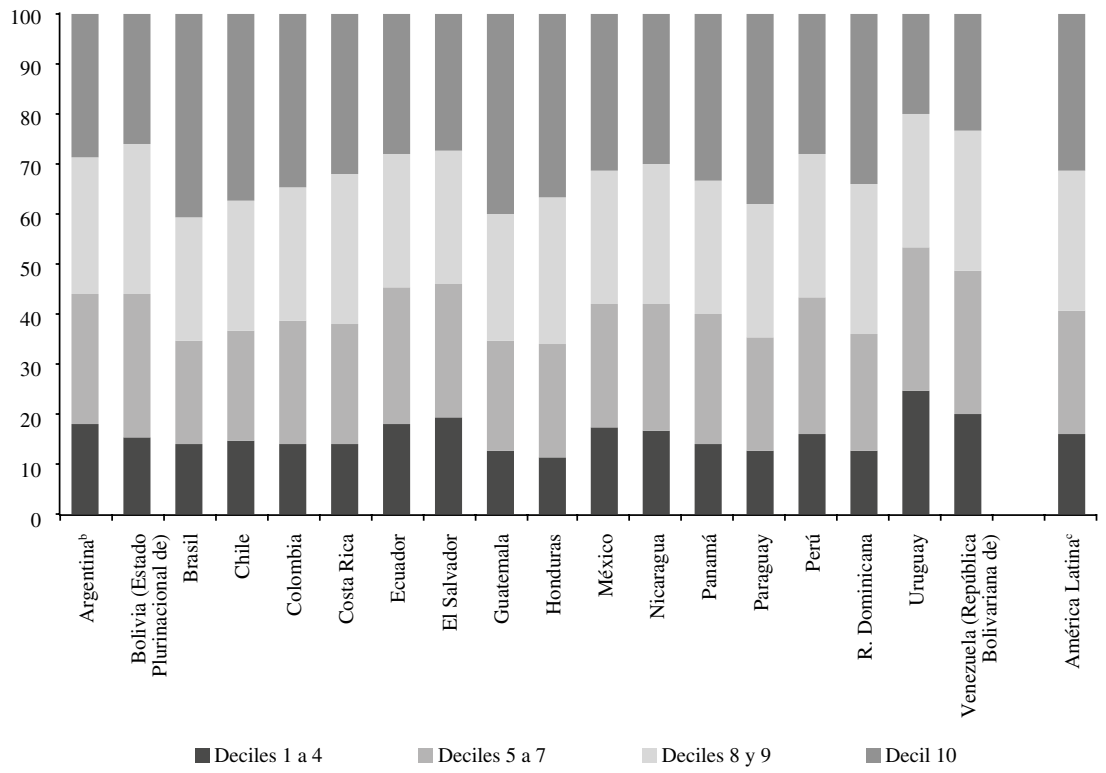

Fuente: Comisión Económica para América Latina y el Caribe (CEPAL), Panorama Social de América Latina 2013 (LC/G.2580), Santiago de Chile, 2013. Publicación de las Naciones Unidas, $\mathrm{N}^{\circ}$ de venta: S.14.II.G.6.

a Los datos corresponden al año 2012, excepto en los casos de Bolivia (Estado Plurinacional de), Chile, Panamá y el Paraguay (2011), Honduras (2010), Nicaragua (2009) y Guatemala (2006).

b Áreas urbanas.

c Promedio simple.

A continuación se presentan y analizan las estimaciones realizadas respecto de los efectos del impuesto a la renta personal, de las contribuciones a la seguridad social y de las transferencias públicas en efectivo en la equidad distributiva. Los resultados del análisis de incidencia se presentan por separado para las pensiones públicas y las demás transferencias públicas en efectivo, así como también, en la siguiente sección, se investigan los efectos redistributivos de la política fiscal para la población en edad de trabajar y en edad de jubilarse.

En el estudio se consideran 17 países latinoamericanos alrededor del año 2011 y se comparan los resultados con los de los países pertenecientes a la OCDE y, en particular, con el promedio de 15 países de la Unión Europea.

Además, dado que el impuesto sobre la renta personal constituye una de las principales debilidades en los países de la región, se evalúa por separado su impacto en la distribución del ingreso.

Los resultados sugieren que la política fiscal beneficia a los grupos de ingresos más bajos de la población, principalmente a través de las jubilaciones y pensiones públicas y de otras transferencias directas en efectivo, ya que el efecto vía impuesto a la renta y contribuciones a la seguridad social es más acotado (véanse el cuadro 1 y el gráfico 2).

Como era de esperar, la efectividad de la política fiscal en la reducción de la desigualdad es diferente entre países. Por una parte, se destacan la Argentina, el Brasil y el Uruguay, donde los impuestos sobre la renta personal, las contribuciones a la seguridad social y las transferencias públicas en efectivo (incluidas las jubilaciones y pensiones) reducen, en conjunto, la desigualdad (medida por el coeficiente de Gini) en torno de un $13 \%$ en promedio.

Otros países donde la reducción de la desigualdad supera al promedio de la región son Chile, Costa Rica, México y Panamá, especialmente por la incidencia de las transferencias y subsidios directos, como el programa Oportunidades en México, Chile Solidario, el programa Avancemos en Costa Rica o el Red Oportunidades en Panamá. En estos tres últimos también tienen un efecto igualador los programas de pensiones y jubilaciones públicas, mientras que en México se destaca el impacto de los impuestos directos. 
CUADRO 1

América Latina (17 países): coeficientes de Gini antes y después de impuestos y transferencias públicas, alrededor de 2011

\begin{tabular}{|c|c|c|c|c|}
\hline País & $\begin{array}{l}\text { Ingreso de } \\
\text { mercado }(\mathrm{A})\end{array}$ & $\begin{array}{c}\text { Ingreso bruto solo } \\
\text { con pensiones }(\mathrm{B}) \\
(\mathrm{B}=\mathrm{A}+\text { pensiones públicas })\end{array}$ & $\begin{array}{c}\text { Ingreso bruto }(\mathrm{C}) \\
(\mathrm{C}=\mathrm{B}+\text { transferencias } \\
\text { públicas en efectivo })\end{array}$ & $\begin{array}{l}\text { Ingreso disponible } \\
\text { en efectivo (D) } \\
\text { (D = C - ISR - CSS) }\end{array}$ \\
\hline Argentina & 0,536 & 0,490 & 0,484 & 0,469 \\
\hline Bolivia (Estado Plurinacional de) & 0,502 & 0,493 & 0,491 & 0,487 \\
\hline Brasil & 0,573 & 0,528 & 0,518 & 0,502 \\
\hline Chile & 0,546 & 0,526 & 0,510 & 0,499 \\
\hline Colombia & 0,531 & 0,537 & 0,531 & 0,520 \\
\hline Costa Rica & 0,528 & 0,510 & 0,503 & 0,491 \\
\hline Ecuador & 0,481 & 0,467 & 0,461 & 0,453 \\
\hline El Salvador & 0,442 & 0,445 & 0,443 & 0,430 \\
\hline Honduras $^{\mathrm{a}}$ & 0,551 & $\ldots$ & $\ldots$ & 0,546 \\
\hline México & 0,496 & 0,494 & 0,484 & 0,460 \\
\hline Nicaragua & 0,465 & 0,464 & 0,465 & 0,452 \\
\hline Panamá & 0,546 & 0,524 & 0,519 & 0,504 \\
\hline Paraguay $^{b}$ & 0,523 & 0,524 & 0,523 & 0,520 \\
\hline Perú & 0,487 & 0,485 & 0,482 & 0,461 \\
\hline República Dominicana & 0,560 & 0,555 & 0,551 & 0,545 \\
\hline Uruguay & 0,449 & 0,411 & 0,400 & 0,381 \\
\hline Venezuela (República Bolivariana de) & 0,393 & 0,384 & 0,384 & 0,379 \\
\hline
\end{tabular}

Fuente: elaboración propia sobre la base de encuestas de hogares.

ISR: impuesto sobre la renta personal; cSs: contribuciones a la seguridad social.

a En Honduras no se pudo tener acceso a las variables sobre jubilaciones, pensiones y subsidios en la encuesta de hogares, por lo que no fue posible estimar su efecto en el coeficiente de Gini.

b En el caso del impuesto sobre la renta en el Paraguay, corresponde a una simulación de acuerdo con el impuesto actualmente vigente.

GRÁFICO 2

América Latina (17 países), OCDE y UE-15: desigualdad de los ingresos de mercado, de los ingresos brutos y de los ingresos disponibles, alrededor de 2011

(Coeficientes de Gini)

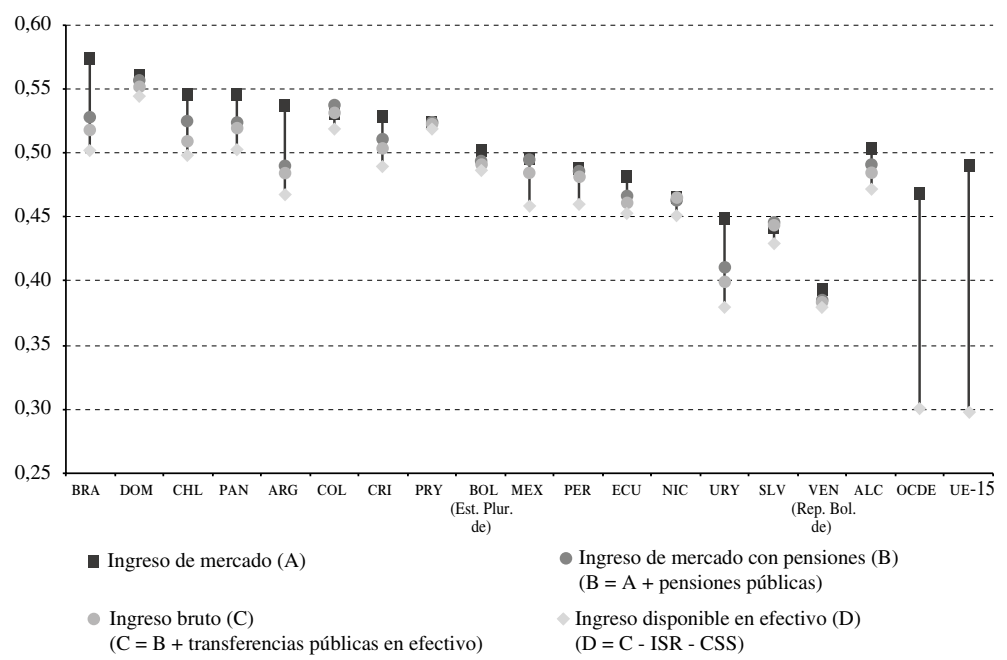

Fuente: elaboración propia sobre la base de encuestas de hogares para América Latina y OCDE.Stat.

ISR: impuesto sobre la renta personal; css: contribuciones a la seguridad social.

Para la Organización de Cooperación y Desarrollo Económicos (OCDE) se ha considerado el promedio de 30 países (sin incluir a Chile y México). UE-15: Unión Europea-15 países

OCDE: Organización para la Cooperación y el Desarrollo Económicos.

ALC: América Latina y el Caribe.

BRA: Brasil; DOM: República Dominicana; CHL: Chile; PAN: Panamá; ARG: Argentina; COL: Colombia; CRI: Costa Rica; PRY: Paraguay; BOL:

Bolivia (Estado Plurinacional de); MEX: México; PER: Perú; ECU: Ecuador; NIC: Nicaragua; URY: Uruguay; SLV: El Salvador; vEN: Venezuela (Repúbica Bolivariana de). 
En el otro extremo se sitúan Colombia y el Paraguay, que presentan una leve repercusión de las transferencias públicas en efectivo y de los impuestos directos en la distribución del ingreso, ya que el índice de Gini disminuye menos de un $2 \%$ luego de la acción fiscal. Además, estos países se encuentran entre los de mayor desigualdad de ingresos de mercado y justamente en ellos la política fiscal debería tener un papel redistributivo más activo. En cambio, los países de la OCDE con una distribución más desigual de los ingresos de mercado tienden a redistribuir más (Joumard, Pisu y Bloch, 2012). En ese sentido, el Brasil, Chile y la Argentina presentan una alta desigualdad antes de la acción fiscal, que en parte es corregida mediante pensiones y jubilaciones públicas, programas de transferencias e impuestos directos.

Más allá de las diferencias entre países, en mayor o menor medida, en todos los casos las transferencias públicas en efectivo (como los programas de transferencias condicionadas u otros) y el impuesto sobre la renta personal disminuyen la desigualdad en la distribución del ingreso (véase el gráfico 3). En general, los sistemas de pensiones públicas también contribuyen a una distribución más igualitaria, excepto en tres países donde la desigualdad aumenta como consecuencia de las pensiones (Colombia, El Salvador y Paraguay).

En promedio, el $61 \%$ de la reducción del coeficiente de Gini de los ingresos de mercado proviene de las transferencias públicas en efectivo (incluidas las pensiones) y el resto de la disminución corresponde al efecto del impuesto sobre la renta y el pago de las contribuciones a la seguridad social. Este resultado, donde las transferencias públicas tienen un mayor papel redistributivo que los impuestos directos, es consistente con los hallazgos de otros estudios regionales.

Una de las ventajas de la metodología aplicada en estas estimaciones es que se ha seguido el enfoque de la OCDE para las distintas definiciones de ingresos, lo que permite la comparación entre ambos grupos de países. En el gráfico 2 se ilustra la gran diferencia respecto del papel que juega la política fiscal en la reducción de la desigualdad del ingreso. Los países de América Latina parten de un coeficiente de Gini para los ingresos de mercado (es decir, antes de transferencias e impuestos directos) que es ligeramente superior al promedio de la OCDE ( 0,50 y 0,47 , respectivamente). Sin embargo, la política fiscal en los países de la OCDE cumple un papel significativo en la reducción de la desigualdad, ya que el coeficiente de Gini baja un 36\% (39\% en el promedio de 15 países de la Unión Europea) y se sitúa en un valor de 0,30 (en términos absolutos, el coeficiente de Gini desciende 17 puntos porcentuales en la OCDE y 19 puntos en la UE-15). En contraste, en la región la disminución promedio de la desigualdad apenas llega al $6 \%$ (o en términos absolutos, a 3 puntos del coeficiente de Gini para el promedio de 17 países), por lo que el Gini del ingreso disponible alcanza un valor promedio de 0,47 GRÁFICO 3

\section{América Latina (17 países): reducción de la desigualdad según instrumento de la política fiscal, alrededor de $\mathbf{2 0 1 1}$ \\ (En puntos porcentuales del coeficiente de Gini)}

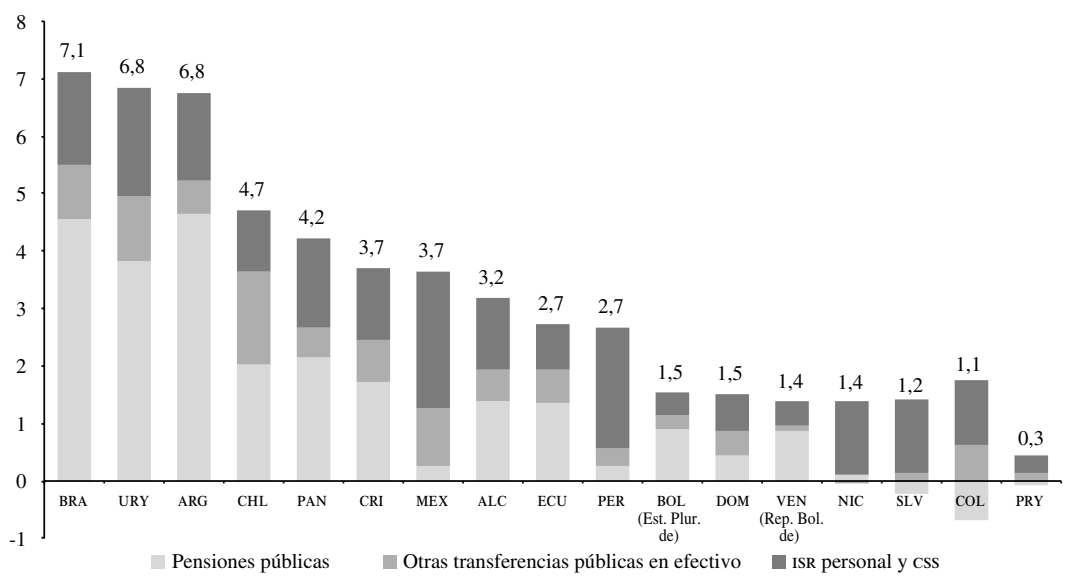

Fuente: elaboración propia sobre la base de encuestas de hogares.

ISR: impuesto sobre la renta personal; css: contribuciones a la seguridad social.

ALC: América Latina y el Caribe.

BRA: Brasil; DOM: República Dominicana; CHL: Chile; PAN: Panamá; ARG: Argentina; COL: Colombia; CRI: Costa Rica; PRY: Paraguay; BOL: Bolivia (Estado Plurinacional de); MEX: México; PER: Perú; ECU: Ecuador; NIC: Nicaragua: URY: Uruguay; SLV: El Salvador; vEN: Venezuela (República Bolivariana de). 
(el mismo valor del coeficiente de Gini del ingreso de mercado de la OCDE).

Las disparidades entre ambos grupos de países también pueden apreciarse en el gráfico 4 , en que se nota el coeficiente de Gini antes y después de transferencias e impuestos directos. La gran mayoría de los países latinoamericanos permanecen cercanos a la recta de $45^{\circ}$, pues el coeficiente de Gini apenas se mueve por el efecto de la política fiscal. En contraposición, los países de la ocDE están muy por debajo de esta recta, lo que indica un efecto mucho más significativo de los instrumentos fiscales.

Una razón de esta diferencia en el poder de la política fiscal para mejorar la distribución del ingreso en América Latina dice relación con la menor carga tributaria, que si bien ha mejorado en los últimos años, aún se encuentra muy por debajo de los niveles de los países pertenecientes a la $\mathrm{OCDE}^{6}$. Esta carga tributaria más baja condiciona el nivel del gasto público y de los programas sociales y, por lo tanto, la amplitud del impacto de la política fiscal en el ingreso de los estratos más bajos. Además, no solo el nivel de la carga tributaria es diferente, sino también

6 Véanse CEPAL (2013a) y OCDE/CEPAL/CIAT (2014). su estructura, ya que en los países de la región dicha estructura está sesgada hacia los impuestos indirectos, mientras que en los países de la ocDE se recauda una importante fracción de impuestos directos, en especial, del impuesto sobre la renta personal que es el que tiene una mayor repercusión redistributiva. Por ejemplo, el promedio de recaudación en la OCDE por concepto de impuesto sobre la renta de los individuos llega al 8,4\% del producto interno bruto (PIB), en cambio en América Latina y el Caribe apenas promedia 1,4 puntos del PIB.

Aparte de lo anterior, la diferencia en la cobertura previsional entre los países de la región y los de la OCDE también es un factor que puede explicar el distinto impacto de la política fiscal. Una fracción importante de los adultos mayores en países con amplia cobertura reciben una pensión no contributiva: en el Uruguay el $11 \%$; en la Argentina el 25\%, en Chile el $26 \%$ y en el Brasil el 36\% (Bosch, Melguizo y Pagés, 2013). De acuerdo con los resultados aquí estimados, en estos cuatro países, además de Costa Rica, los efectos de las pensiones en la desigualdad son más relevantes que en los otros casos latinoamericanos.

Otro indicador que sirve para evaluar la repercusión de las transferencias y los impuestos directos es la razón entre el ingreso promedio del decil superior y el

GRÁFICO 4

América Latina, OCDE y UE-15: desigualdad de los ingresos de mercado y de los ingresos disponibles, alrededor de 2010 y 2011

(Coeficientes de Gini)

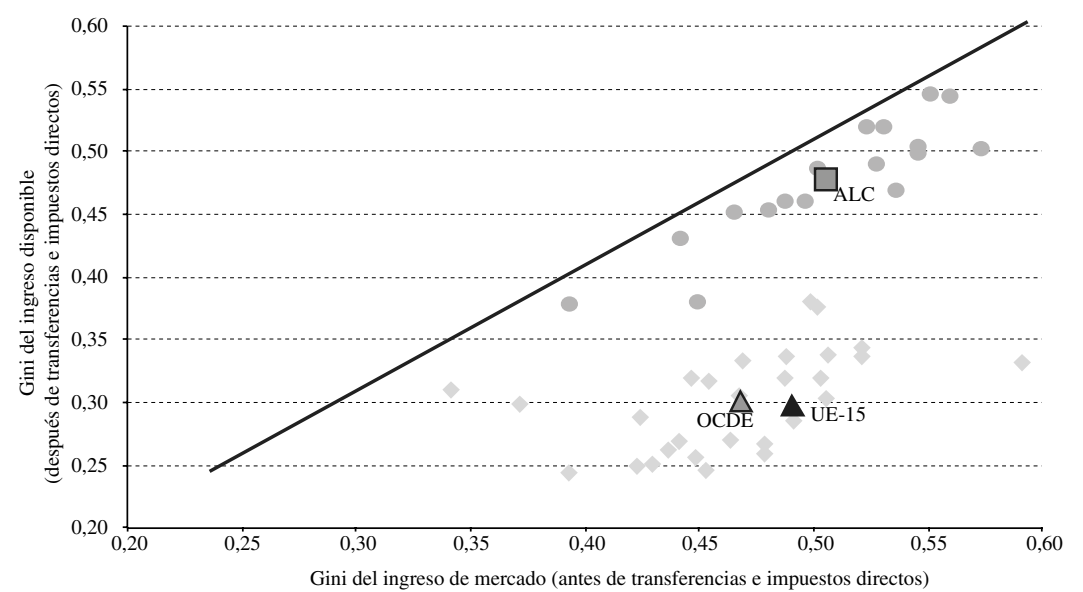

Fuente: elaboración propia sobre la base de encuestas de hogares para América Latina y OCDE.Stat.

Nota: el triángulo más claro representa el promedio para los países de la oCDE, el triángulo más oscuro representa el promedio para la UE-15 y el cuadrado es el promedio para América Latina. Los círculos representan a países de América Latina y el Caribe y los rombos a países de la OCDE.

UE-15: Unión Europea-15 países

OCDE: Organización para la Cooperación y el Desarrollo Económicos.

ALC: América Latina y el Caribe. 
inferior para las diferentes definiciones de ingreso (véase el cuadro 2). Esta relación es útil para complementar el análisis de los coeficientes de Gini, ya que como la mayoría de los programas de transferencias públicas están focalizados en la población más vulnerable (primeros deciles de ingresos) y el impuesto sobre la renta personal se centra en los dos deciles superiores, la distribución no se modifica sustancialmente.

De acuerdo con este indicador, en varios países los beneficios de los sistemas de seguridad social aumentan en mayor proporción los ingresos del decil superior que los del decil 1, por lo que la distribución del ingreso se torna menos igualitaria. Lo contrario sucede con los programas de transferencias públicas directas que benefician notablemente al decil de más bajo ingreso, siendo el instrumento con mayor impacto redistributivo. El Brasil, Costa Rica, México y Panamá están entre los países con los mayores efectos de estos programas, ya que la razón de ingreso disminuye en mayor magnitud. Luego del pago del impuesto a la renta y de las cotizaciones sociales, la cantidad de veces que representa el ingreso del decil 10 en el ingreso del decil 1 vuelve a reducirse, siendo el Brasil, Chile, Costa Rica y México los países que muestran las caídas más significativas.

El efecto final de la acción fiscal para el promedio de los países de la región indica que esta razón pasa de 34 para los ingresos de mercado a 28 para los ingresos disponibles en efectivo (post transferencias e impuestos directos). Si bien esto implica una disminución en la desigualdad de ingresos entre el decil más alto y el más bajo, la región se encuentra muy alejada de los parámetros de la OCDE o de la UE-15, donde el ingreso medio del decil 10 es solo 8 veces el del decil 1, luego de considerar los impuestos y transferencias directas.

CUADRO 2

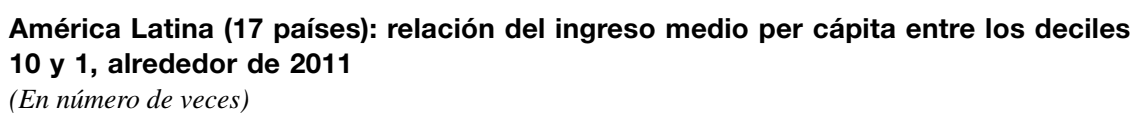

América Latina (17 países): relación del ingreso medio per cápita entre los deciles 10 y 1 , alrededor de 2011

(En número de veces)

\begin{tabular}{|c|c|c|c|c|}
\hline País & $\begin{array}{l}\text { Ingreso de } \\
\text { mercado }(\mathrm{A})\end{array}$ & $\begin{array}{c}\text { Ingreso de mercado } \\
\text { con pensiones }(\mathrm{B}) \\
(\mathrm{B}=\mathrm{A}+\text { pensiones públicas })\end{array}$ & $\begin{array}{c}\text { Ingreso bruto }(\mathrm{C}) \\
(\mathrm{C}=\mathrm{B}+\text { transferencias } \\
\text { públicas en efectivo })\end{array}$ & $\begin{array}{l}\text { Ingreso disponible } \\
\text { en efectivo (D) } \\
\text { (D = C - ISR - CSS) }\end{array}$ \\
\hline Bolivia (Estado Plurinacional de) & 51,2 & 51,1 & 47,5 & 46,1 \\
\hline Brasil & 52,0 & 58,7 & 38,2 & 34,2 \\
\hline Chile & 33,1 & 31,6 & 27,7 & 24,7 \\
\hline Colombia & 34,6 & 39,1 & 36,1 & 33,7 \\
\hline Costa Rica & 39,8 & 36,9 & 32,4 & 29,5 \\
\hline Ecuador & 28,4 & 25,2 & 23,3 & 21,9 \\
\hline El Salvador & 17,9 & 18,7 & 18,3 & 16,8 \\
\hline Honduras ${ }^{\mathrm{a}}$ & 40,6 & $\ldots$ & $\ldots$ & 39,2 \\
\hline México & 27,9 & 28,6 & 24,1 & 20,8 \\
\hline Nicaragua & 21,8 & 22,2 & 22,3 & 20,7 \\
\hline Panamá & 43,8 & 44,5 & 38,9 & 34,8 \\
\hline Paraguay $^{\mathrm{b}}$ & 36,0 & 37,7 & 37,1 & 35,8 \\
\hline República Dominicana & 47,7 & 47,7 & 43,9 & 41,9 \\
\hline Uruguay & 15,6 & 15,0 & 13,0 & 11,3 \\
\hline Venezuela (República Bolivariana de) & 13,8 & 14,4 & 14,3 & 13,8 \\
\hline
\end{tabular}

Fuente: elaboración propia sobre la base de encuestas de hogares.

a En Honduras no se pudo tener acceso a las variables sobre jubilaciones, pensiones y subsidios en la encuesta de hogares, por lo que no fue posible estimar su efecto en el coeficiente de Gini.

b En el caso del impuesto sobre la renta en el Paraguay, corresponde a una simulación de acuerdo con el impuesto actualmente vigente. ISR: impuesto sobre la renta personal; cSs: contribuciones a la seguridad social. 


\section{IV}

\section{Efecto de las transferencias monetarias públicas según grupos poblacionales}

Resulta interesante evaluar el efecto redistributivo de la acción fiscal por grupos poblacionales, de manera de poder analizar el impacto sobre la población en edad de trabajar, por una parte, y de los adultos mayores, por otra (véase el gráfico $5 \mathrm{~A}$ y B).

En las últimas décadas, varios países de la región realizaron reformas a sus sistemas de pensiones e introdujeron esquemas privados de capitalización individual. Estos modelos privados son relativamente jóvenes, por lo que generalmente la mayoría de los pensionados por vejez pertenecen al sistema público y su pensión constituye su única o principal fuente de ingreso. Debido a lo anterior, es de esperar que los efectos de las transferencias públicas en efectivo tengan un impacto superior en la población mayor de 65 años.

En el promedio de países de América Latina, al igual que en la OCDE, las transferencias en efectivo y los impuestos directos reducen sobre todo la desigualdad en la población de adultos mayores, pasando el coeficiente de Gini relativo a este grupo etario de 0,57 a 0,47 en los países latinoamericanos y de 0,73 a 0,28 en los países de la OCDE. En cambio, con respecto a la población en edad de trabajar se parte de una menor desigualdad de los ingresos de mercado y el coeficiente de Gini se reduce bastante menos: de 0,49 a 0,47 en América Latina y de 0,42 a 0,30 en el promedio de la OCDE.

En cuanto a los resultados por países, en el caso de la población en edad de trabajar, en los que más se reduce la desigualdad de los ingresos de mercado vía transferencias e impuestos directos son el Uruguay, el Brasil y la Argentina; y le siguen México, Panamá, Chile y Costa Rica.

A. Población en edad de retiro

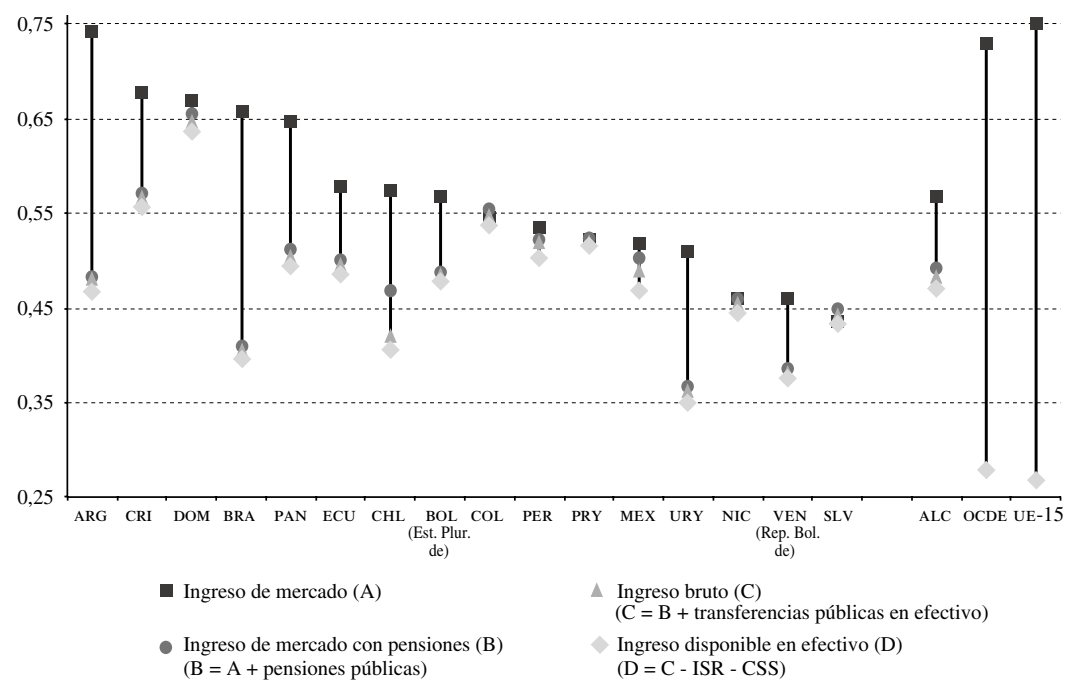


B. Población en edad de trabajar

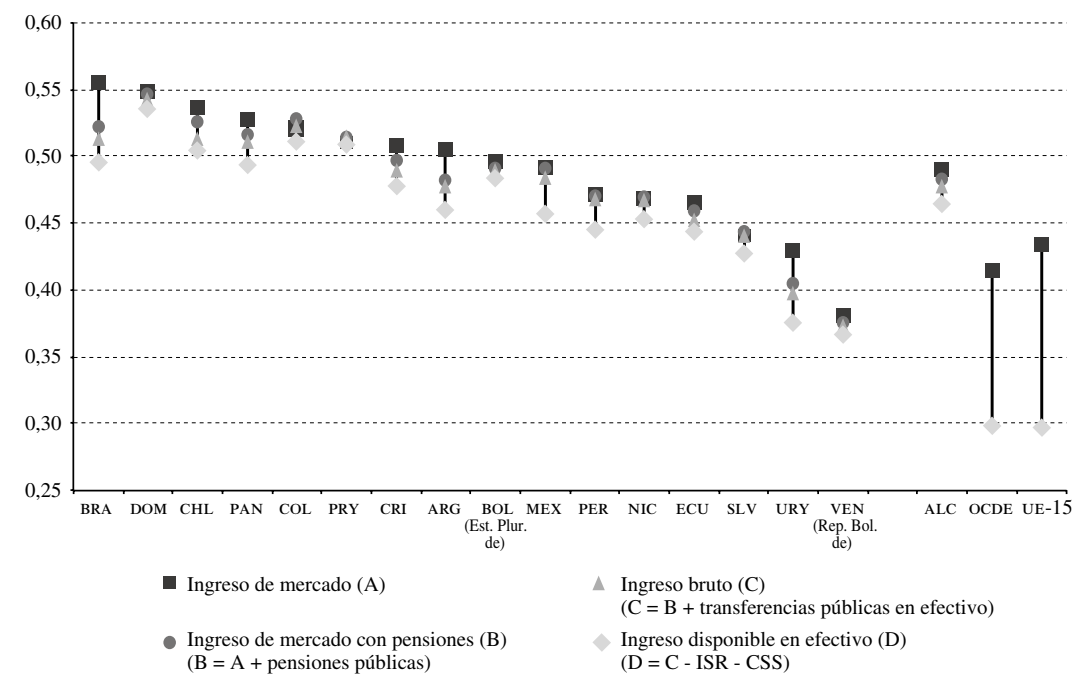

Fuente: elaboración propia sobre la base de encuestas de hogares.

ISR: impuesto sobre la renta personal; css: contribuciones a la seguridad social.

Para la Organización de Cooperación y Desarrollo Económicos (OCDE) se ha considerado el promedio de 30 países (sin incluir a Chile ni a México). UE-15: Unión Europea-15 países.

OCDE: Organización para la Cooperación y el Desarrollo Económicos.

ALC: América Latina y el Caribe.

BRA: Brasil; DOM: República Dominicana; CHL: Chile; PAN: Panamá; ARG: Argentina; COL: Colombia; CRI: Costa Rica; PRY: Paraguay; BOL:

Bolivia (Estado Plurinacional de); MEX: México; PER: Perú; ECU: Ecuador; NIC: Nicaragua; URY: Uruguay: SLv: El Salvador; ven: Venezuela (República Bolivariana de).

\section{RECUADRO 2}

\section{El TRATAMIENTO DE LAS PENSIONES EN LOS ESTUdios DE INCIDENCIA}

Un caso complejo y sujeto a debate es el tratamiento de las pensiones en este tipo de análisis. En los países de la región existen sistemas públicos de pensiones y sistemas privados, como así también pensiones contributivas y no contributivas. Esto puede afectar a las comparaciones internacionales, dado que las pensiones podrían considerarse como parte de los ingresos de mercado o como una transferencia pública en efectivo.

En este estudio se ha seguido el criterio de la OCDE (2008), que consiste en incluir las pensiones profesionales y privadas en la definición de ingresos de mercado, mientras que las pensiones provenientes de los sistemas públicos de seguridad social se tratan como transferencias en efectivo, es decir, forman parte del ingreso bruto. De acuerdo con Lustig, Pessino y Scott (2013), existen argumentos en favor de ambos tratamientos de las pensiones contributivas, ya sea como parte de los ingresos del mercado, dado que constituyen un ingreso diferido, o como una transferencia de gobierno sobre todo en sistemas que tienen un gran componente subsidiado.

En la medida en que la información disponible en las encuestas lo permitió, se realizó otro análisis de incidencia considerando a las pensiones contributivas de los sistemas públicos de seguridad social como parte de los ingresos de mercado. En este caso, el efecto de las transferencias públicas vía pensiones se reduce considerablemente en el Brasil y el Uruguay (no así en la Argentina). No obstante, estos países siguen estando entre los de mayor poder redistributivo de la acción fiscal, cuyo efecto total (con esta medición alternativa) es similar al alcanzado por Chile y México.

Fuente: elaboración propia. 
Entre la población en edad de retiro también se destacan el Brasil, la Argentina, el Uruguay y Chile, con una caída del coeficiente de Gini cercana o superior al 30\% y Panamá, Costa Rica, Venezuela (República Bolivariana de), el Ecuador y Bolivia (Estado Plurinacional de) con disminuciones en la desigualdad entre el $15 \%$ y el $23 \%$. Resalta de esta manera la marcada influencia de las transferencias por efecto de las pensiones en la diferencia entre el coeficiente de Gini del ingreso de mercado y el del ingreso disponible en la población de 65 años y más, sobre todo en aquellos países donde la tasa de dependencia de adultos mayores es alta, principalmente en la Argentina y el Uruguay (véase el gráfico 6).

Queda claro entonces que el grado de cobertura de los sistemas públicos de pensiones tiene alta incidencia en la redistribución del ingreso disponible (aunque depende de las tasas de dependencia de cada país), y por ello no resulta sorprendente que el efecto de las transferencias sea mínimo en países con baja cobertura (véase Bosch, Melguizo y Pagés, 2013). Es evidente que la acción fiscal tiene mayor incidencia en la distribución del ingreso en aquellos países donde existen avances importantes para universalizar la cobertura de pensiones, pues la mayoría de los adultos mayores no cuentan con ingresos propios significativos.

Sin embargo, es muy probable que este tipo de intervenciones no sean suficientes, pues la desigualdad sigue siendo un tema pendiente tanto en la población en edad de trabajar como en la de adultos mayores.

GRÁFICO 6

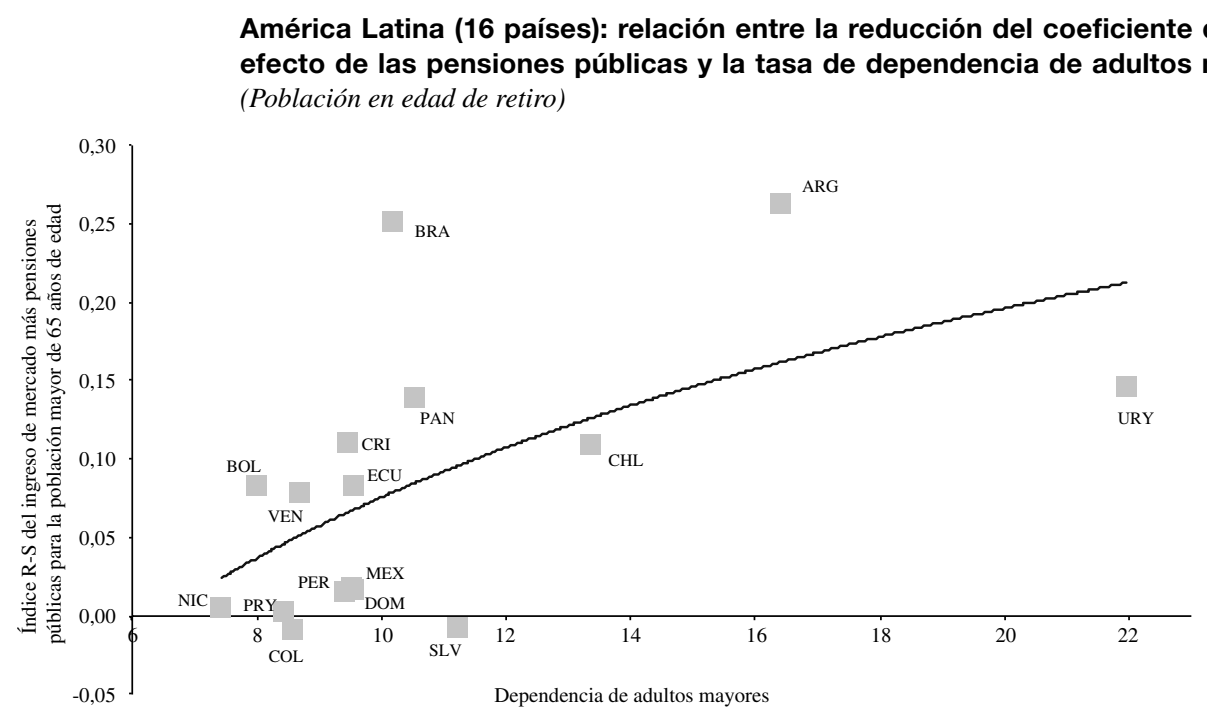

Fuente: elaboración propia sobre la base de encuestas de hogares y Centro Latinoamericano y Caribeño de Demografía (CELADE)-División de Población, base de datos de población.

Nota: R-s Reynolds Smolensky.

BRA: Brasil; DOM: República Dominicana; CHL: Chile; PAN: Panamá; ARG: Argentina; COL: Colombia; CRI: Costa Rica; PRY: Paraguay; BOL: Bolivia (Estado Plurinacional de); MEX: México; PER: Perú; ECU: Ecuador; NIC: Nicaragua; URY: Uruguay; sLv: El Salvador; ven: Venezuela (República Bolivariana de). 


\section{Progresividad e impactos redistributivos del impuesto a la renta personal}

Con el fin de evaluar la progresividad o regresividad del impuesto a la renta de las personas físicas, en primer lugar se estiman las tasas medias que paga cada decil. En general, se aprecia que a mayor nivel de ingresos (deciles superiores) mayor es la proporción de impuestos que se paga, es decir, el impuesto con base en la renta personal es progresivo (véase el cuadro 3). Sin embargo, la curva de progresión de tasas medias no es siempre creciente (por ejemplo, en Colombia y el Paraguay), por lo que también se estima el índice de Kakwani que determina que este tributo es progresivo en todos los países, ya que su valor es positivo.

En la mayor parte de los países, el $90 \%$ o más del impuesto es soportado por el $20 \%$ de ingresos más elevados, mientras que el grupo de hogares pertenecientes al $80 \%$ de ingresos inferiores no aporta a la recaudación del tributo o lo hace en una fracción muy pequeña.

Empero, se observa que la tasa efectiva que pagan los individuos pertenecientes al decil de mayores ingresos apenas alcanza un valor promedio del 5,4\%, habiendo países donde se paga solo entre un $1 \%$ y un $3 \%$ del ingreso bruto. Si bien las tasas legales máximas del impuesto a la renta personal se sitúan entre el $25 \%$ y el $40 \%$, las tasas efectivas que paga el decil superior son muy bajas como consecuencia de la evasión y la elusión, las exenciones, las deducciones y el tratamiento preferencial de las rentas de capital, que en algunos países no están gravadas y en otros tributan a una tasa más baja que las rentas del trabajo.

De esta manera, si bien el diseño del impuesto a la renta personal es progresivo en todos los países, su impacto redistributivo es muy limitado como consecuencia de los bajos niveles de recaudación. En otras palabras, el coeficiente de Gini se reduce en promedio un $2 \%$ por la acción de este impuesto (o, en términos absolutos, un punto porcentual del coeficiente de Gini), con ciertas diferencias entre los países.

Con el objetivo de evaluar si la distribución de los impuestos sobre la renta altera o no el ordenamiento de los individuos de acuerdo con su nivel de ingresos, se construye el indicador de Atkinson-Plotnick. Los países donde prácticamente se mantiene el ordenamiento de los contribuyentes son el Ecuador, Honduras, el Paraguay y Venezuela (República Bolivariana de). Por el contrario, se observa un mayor cambio en el ordenamiento de los individuos, debido a la acción del impuesto a la renta personal, en la Argentina, México y el Uruguay.

\section{RECUADRO 3}

INCIDENCIA DEL IMPUESTO AL VALOR AGREGADO (IVA) Y DE LOS SISTEMAS TRIBUTARIOS EN SU CONJUNTO

Como se sabe, el IVA es el impuesto dominante en todos los países de la región, pero su diseño e impacto en la distribución del ingreso son muy variables entre países, pues en algunos casos existen tasas uniformes (Chile, El Salvador), en otros tasas variables (Argentina, Colombia) y en otros más, canastas básicas exentas (México, Costa Rica, República Dominicana) (para el detalle de los sistemas véase CEPAL, 2013a). Los estudios disponibles para América Latina dan cuenta de una fuerte regresividad del IVA en países como Bolivia (Estado Plurinacional de), Brasil, Chile, El Salvador, Guatemala, el Paraguay y el Uruguay. En este último caso, el estudio es anterior a las medidas de exención de IVA a los beneficiarios de programas sociales, las que se han puesto en práctica a partir de 2012 .

En los países que cuentan con información del coeficiente de Gini antes y después de impuestos directos e indirectos, el papel redistributivo de los sistemas tributarios en su conjunto no supera el $1,5 \%$ en ninguno de los casos y el índice de Reynolds-Smolensky se sitúa entre $-0,008$ y 0,009. En otras palabras, la acción de la política tributaria no logra modificar la distribución del ingreso de manera relevante en la región, en parte debido a la baja recaudación del impuesto a la renta y en parte por el carácter regresivo del IVA, que compensa el potencial impacto progresivo del ISR.

Fuente: Comisión Económica para América Latina y el Caribe (CEPAL), "Panorama fiscal de América Latina y el Caribe: Hacia una mayor calidad de las finanzas públicas" (LC/L.3766), Santiago de Chile, 2014.

ISR: impuesto sobre la renta personal. 


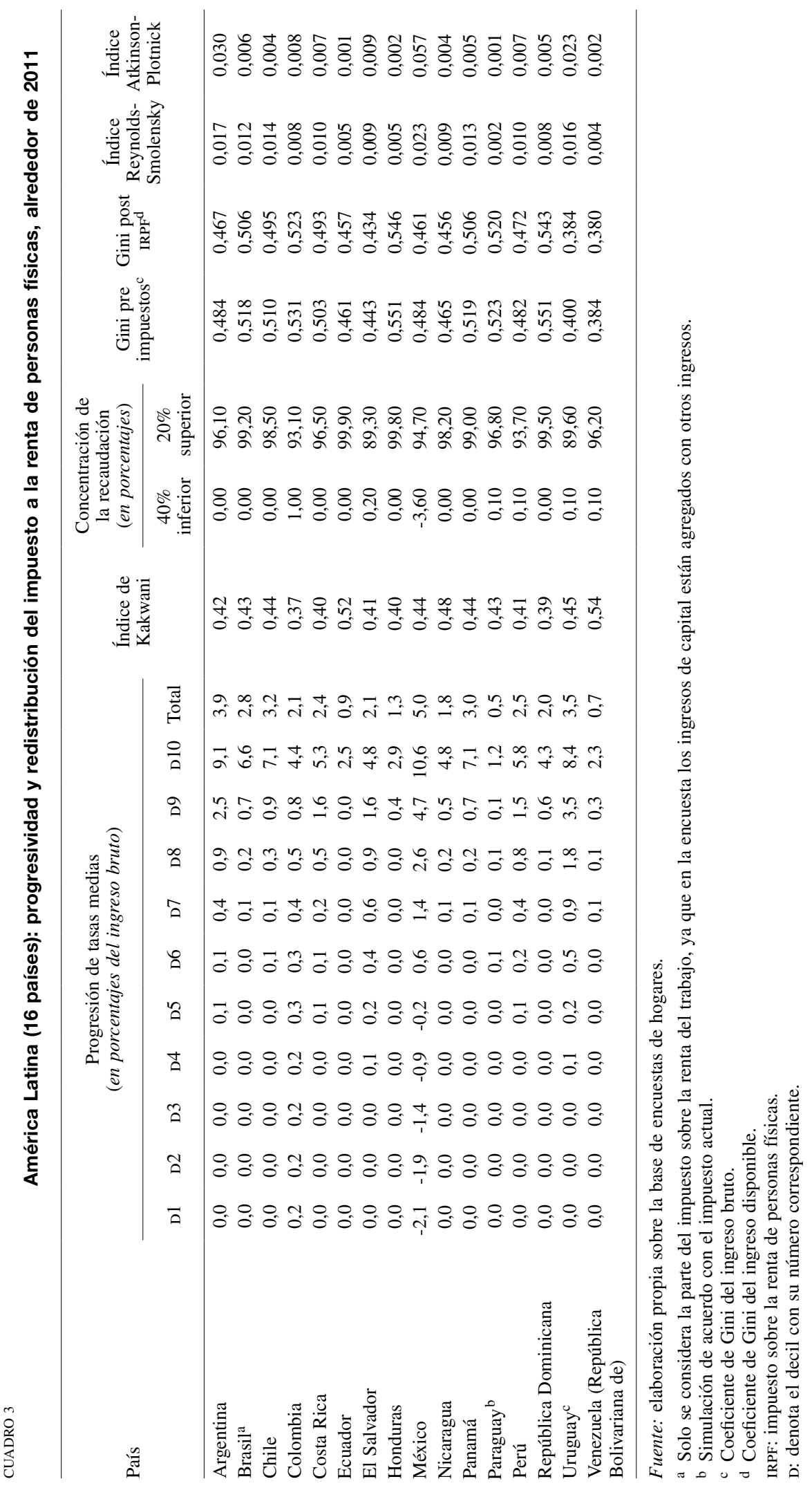




\section{VI}

\section{Simulaciones de política}

Como se ha reiterado en numerosos documentos y foros, la debilidad — relativa y absoluta— del impuesto a la renta es el principal problema estructural de los sistemas tributarios de América Latina. En la política tributaria se ha privilegiado la eficiencia, pretendiendo que el impuesto a la renta afecte lo menos posible a las decisiones de ahorro e inversión y aproximando, en ciertos casos, la base imponible a una base de consumo en vez de la tradicional base de ingresos.

En el camino, por cierto, se han sacrificado los atributos de equidad y simplicidad; el principal aspecto que afecta a la equidad del impuesto a la renta es el tratamiento preferencial que reciben las rentas de capital, lo que provoca una asimetría con respecto a la tributación de las rentas del trabajo. Otras características del impuesto que afectan a la equidad son una unidad de tributación que considera a los individuos en vez de los hogares, lo que estimula el fraccionamiento de rentas para bajar la tributación, y rentas exentas que favorecen más a los percentiles de mayores ingresos (véase Jorrat, 2011).

En el decenio en curso, varios países de la región han llevado a cabo una serie de reformas tributarias con que se ha procurado mejorar la recaudación mediante el aumento de las tasas, la reducción de las exenciones, la implementación de sistemas de imposición dual en algunos casos, la modificación o creación de impuestos mínimos y el aumento de la fiscalización a los grandes contribuyentes ${ }^{7}$. Sin embargo, la incidencia de estas reformas en la desigualdad sigue siendo muy limitada en la mayoría de los países, como lo muestran los estudios recientes de la CEPAL ${ }^{8}$. Por ello, para una mejora sustantiva de la equidad tributaria es fundamental incrementar la tributación de las rentas del capital y las tasas medias efectivas de los últimos deciles o centiles, que son comparativamente bajas.

En consecuencia, es importante evaluar las reformas bajo el prisma de la equidad en la distribución del ingreso disponible y, con tal objetivo, a continuación se describen

\footnotetext{
7 Para una descripción detallada de las reformas implementadas en la región durante el período 2007-2013, véase CEPAL (2014a y 2013a).

${ }^{8}$ Los estudios para Bolivia (Estado Plurinacional de), Chile, el Perú, El Salvador, el Ecuador, Guatemala y Honduras muestran que la incidencia en la distribución del ingreso de las reformas al impuesto a la renta ha sido más bien limitada.
}

las reformas potenciales del impuesto a la renta personal que se han considerado en esta investigación?:

i) Derogación de los principales gastos tributarios que benefician a las personas naturales, sin modificar los tramos de la escala ni las tasas marginales. Es decir, se gravan todos los ingresos percibidos, incluidos los de capital y de transferencias de cualquier origen. En los países en que el IRPF (impuesto sobre la renta de las personas físicas) contiene tasas diferenciadas, según fuente de ingreso, se aplican los tramos y las tasas progresivas que gravan los ingresos laborales a todos los tipos de ingresos.

ii) Impuesto a la renta familiar ${ }^{10}$ en que se consideren los siguientes elementos:

- La unidad de tributación son los hogares en vez de los individuos.

- La misma base imponible del escenario i), pero expresada como renta equivalente y sobre la cual se aplica la escala actual de tasas.

- Se ajustan todos los tramos de la escala de tasas con un mismo factor, de tal forma que la recaudación sea igual a la obtenida en el escenario i).

iii) Impuesto estándar: se evalúa la aplicación de una escala de tasas idéntica para todos los países sobre una base imponible amplia, sin gastos tributarios. Con ello se pretende evaluar las diferencias de potencial redistributivo del impuesto en los distintos países. Se considera la misma base imponible del escenario i) y se reemplaza la escala de tasas del impuesto personal de cada país por una escala común.

Como se sabe, el coeficiente de Gini se mueve poco con las simulaciones que afectan marginalmente a los ingresos de los deciles superior o inferior, como en este tipo de ejercicios. En otras palabras, desde el punto de vista impositivo, más que simular medidas detalladas también es interesante invertir el ejercicio, asumiendo que se logran incrementar las tasas medias efectivas de los deciles más altos — sin precisar cómo—, para luego

\footnotetext{
9 Más detalles pueden consultarse en Jorrat (2011), quien aplica simulaciones similares para algunos países de la región.

$10 \mathrm{Si}$ bien esta medida puede ser de difícil aplicación en la práctica, en este estudio se realiza una serie de ejercicios donde se evalúa un amplio espectro de reformas potenciales, sin considerar su factibilidad jurídica.
} 
estimar su incidencia en la distribución del ingreso ${ }^{11}$. Por lo tanto, se hacen dos ejercicios adicionales:

iv) Sobre la base del escenario i) se incrementa al $20 \%$ la tasa efectiva del último decil. Para tal fin se levanta el supuesto de que los trabajadores informales no pagan el impuesto a la renta personal en el último decil.

v) Además de aplicar una tasa efectiva del $20 \%$ al decil 10, se aumenta a $10 \%$ la carga de los deciles 8 y 9 , también sobre la base del escenario i).

Igualmente, en cada uno de los cinco escenarios se evalúa el efecto de redistribuir, a través de transferencias en efectivo, la mayor recaudación obtenida con respecto a la situación actual. Como se trata de simulaciones estáticas - donde no se toman en cuenta efectos de segunda vuelta — no es necesario precisar cómo se asignan estos mayores recursos, pues se supone una distribución en partes iguales entre los individuos pertenecientes a los tres deciles de menores ingresos.

Los resultados denotan que existe un amplio espacio para mejorar el poder redistributivo del impuesto a la

\footnotetext{
${ }^{11}$ Este ejercicio dista de ser vano; por ejemplo, en Chile la reforma tributaria de 2014 apunta a más que doblar, mediante cambios de tasas, eliminación de exenciones y una mayor fiscalización, la tasa media efectiva del decil 10, la que alcanzaría en régimen una cifra superior al 20\%, similar a la de la Unión Europea (véase el documento "Artículo 1, el corazón de la Reforma Tributaria" [en línea] http:// reformatributaria.gob.cl/documentos.html).
}

renta personal en América Latina (véase el gráfico 7). La equidad vertical y la horizontal mejoran con la eliminación de los principales gastos tributarios del impuesto a la renta (incluso sin considerar el efecto de redistribuir la recaudación adicional). Cuando se pasa a un régimen de impuesto familiar, la desigualdad disminuye un poco más ${ }^{12}$. La aplicación de un impuesto estándar (escenario iii) en todos los países, sobre una base imponible amplia, también mejora el papel redistributivo del impuesto a la renta, aunque muestra un mayor cambio en el ordenamiento de los individuos (indicador de Atkinson-Plotnick).

Si los países de la región lograsen incrementar hasta en $20 \%$ la tasa efectiva que paga el decil superior en la escala de ingresos, el efecto redistributivo del impuesto a la renta personal, medido por el índice de ReynoldsSmolensky, aumentaría considerablemente. Para lograr este aumento en la tasa efectiva se han eliminado los principales gastos tributarios, las rentas de capital han recibido el mismo tratamiento impositivo que las del trabajo y se ha levantado el supuesto de evasión. De acuerdo con las estimaciones realizadas, para alcanzar tal efecto la tasa media legal aplicable a los contribuyentes del último decil se ubicaría entre el 20\% y el 30\% según

\footnotetext{
12 Este mayor efecto redistributivo del impuesto familiar es consistente con lo obtenido por Jorratt (2011) en sus simulaciones para el Ecuador, Guatemala y el Paraguay.
}

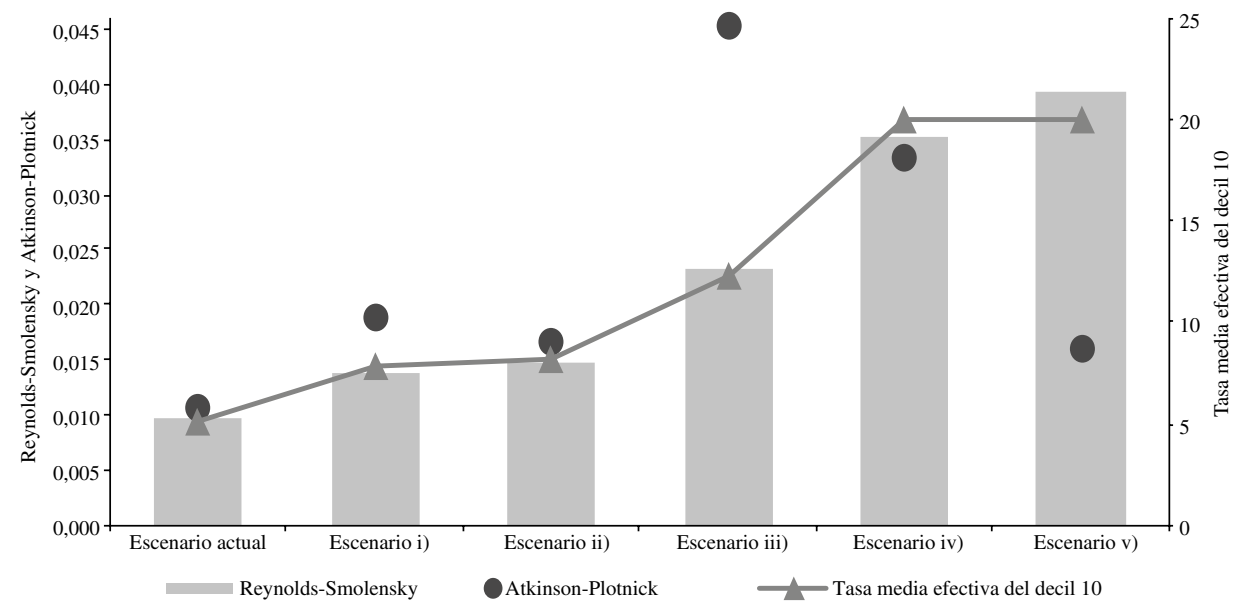

Fuente: elaboración propia sobre la base de encuestas de hogares.

Nota: escenarios sin redistribuir la recaudación adicional hacia los deciles inferiores.

Escenarios: i) Impuesto a la renta de personas físicas sin gastos tributarios; ii) Impuesto familiar; iii) Impuesto estándar; iv) Tasa del $20 \%$ al decil 10, y v) Tasa del $20 \%$ al decil 10 y de $10 \%$ a los deciles 8 y 9. 
el país. Estos valores son inferiores o cercanos a las tasas máximas vigentes en cada legislación, con excepción del Paraguay que tiene una alícuota legal máxima del $10 \%$.

El hecho de gravar además a los deciles 8 y 9 con una tasa media efectiva del 10\% también disminuye la desigualdad.

Los resultados de los últimos dos escenarios ilustran ciertas debilidades del impuesto a la renta personal en los países de la región: en particular, el alto nivel de evasión y elusión; estructuras impositivas que suelen dejar sin gravar a ciertos ingresos y el elevado nivel de ingreso a partir del cual se aplican las tasas máximas.

A pesar de que en los primeros escenarios -que mantienen en parte o totalmente la estructura de tramos y tasas del impuesto actual- una ampliación de la base imponible incrementa las tasas medias efectivas, especialmente las de los últimos deciles, estas aún se mantienen relativamente bajas (véase el gráfico 7). Entre las razones de este comportamiento se destaca que, a diferencia de la experiencia de los países de la OCDE, los países de la región han reducido sus tasas máximas, convergiendo hacia las tasas de las personas jurídicas (Cetrángolo y Gómez Sabaini, 2007). Este factor se ve agravado por el alto nivel de ingreso a partir del cual se aplican las tasas máximas. En promedio, en América Latina la tasa máxima empieza a aplicarse a ingresos nueve veces mayores que el PIB per cápita, en comparación con 6,5 veces en el conjunto de los países de ingreso medio (Ter-Minassian, 2012). Los resultados de los últimos dos escenarios, y en menor medida el del escenario iii), demuestran que el hecho de lograr un aumento en las tasas medias efectivas - superando ciertas debilidades en la estructura del impuesto actual junto con una diminución de la evasión fiscal—, conduciría a alcanzar una mayor redistribución del ingreso.

Un argumento común en contra de reformas como las aquí simuladas es que estas podrían reducir la progresividad del impuesto, ya que en la mayoría de los países las deducciones permitidas procuran darle mayor progresividad al sistema. La disminución del índice de Kakwani en el escenario de eliminación de los principales gastos tributarios pareciera validar este argumento (el indicador cae de un valor promedio de 0,44 a 0,37). Sin embargo, de acuerdo con lo señalado por Díaz de Sarralde, Garcimartín y Ruiz-Huerta (2010), la descomposición propuesta por Kakwani podría no ser apropiada para analizar reformas tributarias que aumenten la recaudación similares a las aquí presentadas, ya que como el cálculo del índice de Kakwani se ve influido por cambios en la tasa media efectiva, una caída en este podría reflejar una disminución de la progresividad del impuesto o simplemente un cambio en la tasa media efectiva, como lo que ocurre en estas simulaciones. Así, la ampliación de la base imponible conduce a un incremento de las tasas efectivas del impuesto, especialmente en los dos deciles de mayores ingresos y el efecto redistributivo es mayor que en el caso actual (véase el gráfico 7).

De hecho, en los escenarios considerados, la mayor equidad vertical se alcanza por medio del importante incremento de las tasas medias efectivas. Además, es relevante notar que el aumento de dichas tasas se debe a que los deciles superiores pagan una mayor proporción del impuesto en relación con su ingreso y, además, el diferencial entre las tasas que pagan los deciles superiores y los inferiores se amplía como consecuencia de estas medidas.

A su vez, se observa que los efectos sobre el coeficiente de Gini son relativamente menores en los escenarios antes descritos, donde no se redistribuyen los recursos generados por la mayor recaudación obtenida. Suele afirmarse, sobre la base de este tipo de ejercicios, que el efecto de los sistemas tributarios - y en particular del impuesto a la renta - es relativamente menor en la distribución del ingreso; pero importa estimar el efecto total, considerando el destino que se le da a aquellos recursos.

En efecto, el aumento de las tasas efectivas, junto con la posterior redistribución de estos ingresos hacia los tres deciles inferiores, permitiría reducir coeficiente de Gini para el promedio de la región en un rango que va desde 3 puntos porcentuales, en el caso del impuesto sin gastos tributarios y el familiar, hasta 13 puntos porcentuales en el escenario de aumento de la tasa efectiva que se aplica a los tres deciles superiores de la escala de ingresos (véase el gráfico 8). De esta forma, el coeficiente de Gini promedio del ingreso disponible para la región se ubicaría entre 0,45 y 0,36, dependiendo del escenario de política considerado. Esta última cifra se acerca bastante al índice promedio de los países de la OCDE o de 15 países de la Unión Europea, que se sitúa en 0,30 .

Dado que el impuesto a la renta recae en mayor medida sobre el decil superior, la cantidad de veces que representa el ingreso del decil 10 en el ingreso del decil 1 se reduce de 29,5 a 27,9 en la situación actual para el promedio de los países de la región (véase el gráfico 9). La eliminación de las principales deducciones y exenciones y las demás alternativas de políticas apenas llevan esta razón a 26 o 27 según el escenario considerado, mientras que las simulaciones que aumentan hasta $20 \%$ la tasa efectiva del decil 10 , reducen a 23,6 las veces que el ingreso promedio de este decil representa en el decil más bajo. 
GRÁFICO 8
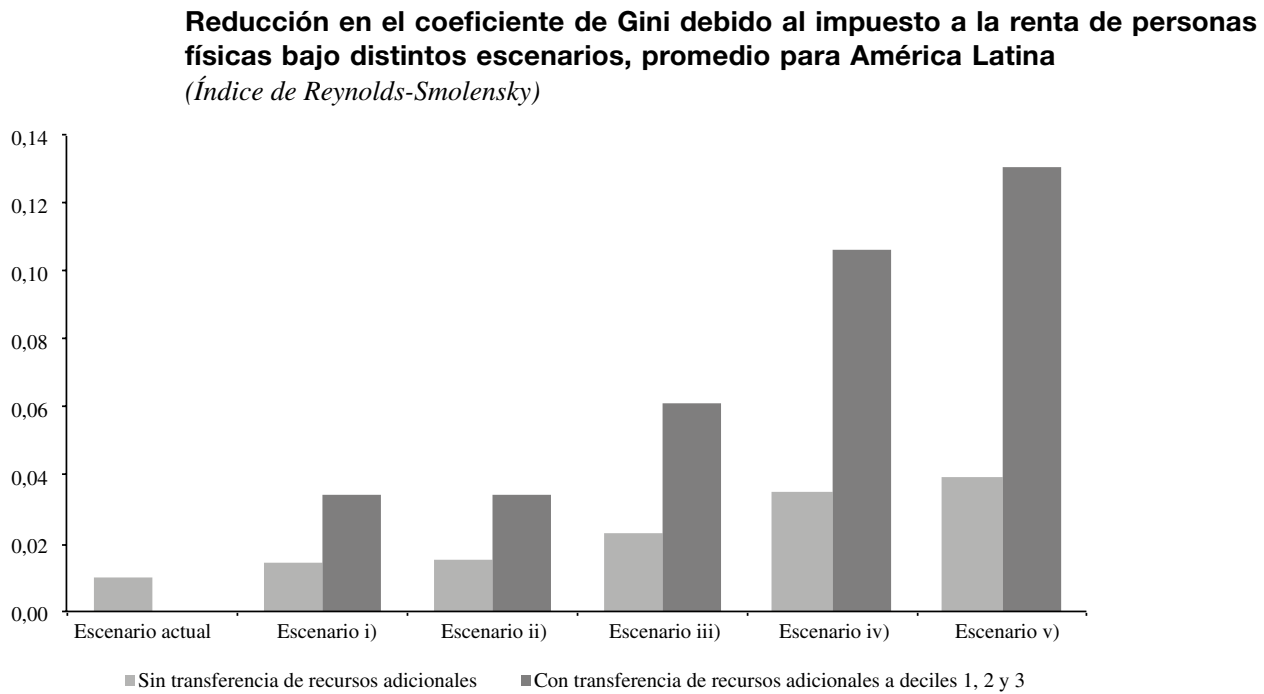

Fuente: elaboración propia sobre la base de encuestas de hogares.

Nota: escenarios: i) Impuesto sobre la renta de personas físicas sin gastos tributarios; ii) Impuesto familiar; iii) Impuesto estándar; iv) Tasa del $20 \%$ al decil 10 , y v) Tasa del $20 \%$ al decil 10 y del $10 \%$ a los deciles 8 y 9.

GRÁFICO 9
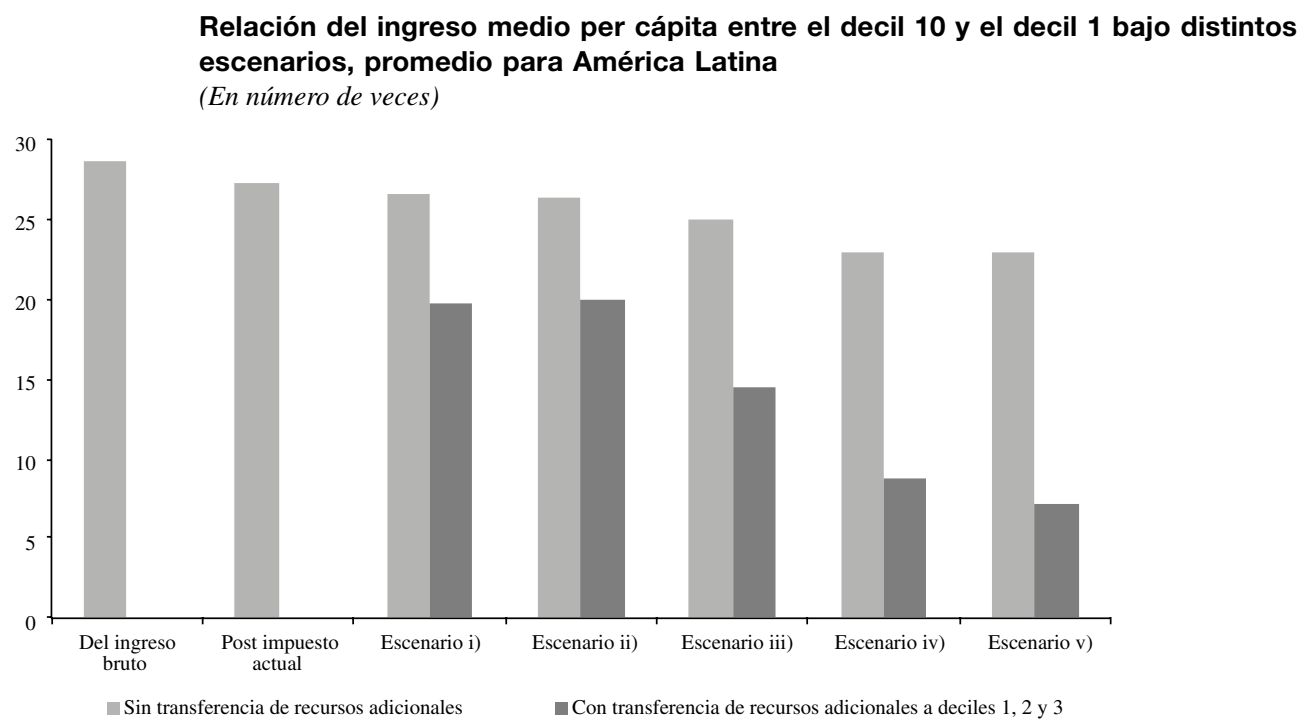

Fuente: elaboración propia sobre la base de encuestas de hogares.

Nota: escenarios: i) Impuesto sobre la renta de personas físicas sin gastos tributarios; ii) Impuesto familiar; iii) Impuesto estándar; iv) Tasa del $20 \%$ al decil 10, y v) Tasa del $20 \%$ al decil 10 y del $10 \%$ a los deciles 8 y 9.

El efecto final de estas políticas, es decir, cuando se redistribuye la recaudación excedente a los tres deciles inferiores, sitúa esta razón en un rango entre 21 y 7 según el escenario de política analizado. Este último valor implica una significativa disminución en la desigualdad de ingresos entre el decil más alto y el más bajo, y deja a la región en una relación de ingresos similar al promedio de los países de la OCDE y de 15 países de la Unión Europea (cuyas razones son 8,3 y 7,8 , respectivamente). 


\section{VII}

\section{Reflexiones finales}

En América Latina, la política fiscal juega aún un papel limitado a la hora de mejorar la distribución del ingreso disponible. Si bien los países de la región parten de niveles de desigualdad de los ingresos de mercado solo levemente superiores a los de la OCDE, la política fiscal en estos últimos cumple un papel significativo en la reducción de la desigualdad, ya que el coeficiente de Gini baja un 36\% luego de las transferencias e impuestos directos, en comparación con solo un $6 \%$ en los países latinoamericanos (en términos absolutos, el coeficiente de Gini cae 17 puntos porcentuales en la OCDE y apenas 3 puntos para el promedio de 17 países de América Latina).

Más allá de las claras diferencias entre países que se han ilustrado en los cálculos previos, en promedio, el $61 \%$ de la reducción del coeficiente de Gini en América Latina proviene de las transferencias públicas en efectivo (incluidas las pensiones) y el resto del impuesto a la renta personal y el pago de las contribuciones a la seguridad social. Esto indica que dicho impuesto sobre la renta constituye una de las principales áreas de la política fiscal que es necesario fortalecer.

En este sentido, las simulaciones de potenciales reformas al impuesto a la renta personal evidencian que en la región existe espacio para ampliar el poder redistributivo de este tributo. La equidad vertical mejora con la eliminación de los principales gastos tributarios, como también con un régimen de impuesto familiar. La aplicación de un impuesto estándar, sobre una base imponible amplia, incrementa aún más el papel redistributivo del impuesto. En el caso hipotético de que los países de la región acrecentaran hasta el 20\% la tasa efectiva que paga el decil superior en la escala de ingresos, el efecto redistributivo del impuesto a la renta personal aumentaría considerablemente. Si además la mayor recaudación obtenida se redistribuye hacia los deciles inferiores, la acción fiscal sí tendría un impacto significativo en el coeficiente de Gini.
La evaluación del efecto redistributivo de estas potenciales reformas comprueba la importancia de promover acciones que combatan la evasión y elusión fiscal (en especial del impuesto sobre la renta personal); de otorgar a las rentas de capital un tratamiento similar al aplicado a las rentas provenientes del trabajo; de reducir los tratamientos preferenciales y rebajar el nivel de ingreso a partir del cual se aplican las tasas máximas en concordancia con los rangos establecidos en otras regiones.

Además, si la mayor recaudación obtenida a través de estas medidas se destina a reforzar las transferencias percibidas por los deciles de menores ingresos, se puede triplicar el efecto redistributivo de la política fiscal.

En conclusión, los resultados de este estudio sugieren que uno de los grandes desafíos que sigue enfrentando la región es mejorar el poder redistributivo de la política fiscal, tanto en lo que se refiere a los impuestos como a los gastos, a objeto de promover una mayor igualdad en la distribución del ingreso disponible y una mayor reducción de los niveles de pobreza. Una ampliación de este enfoque para considerar las transferencias en especie (básicamente por servicios educativos y de salud), como asimismo la aplicación del ejercicio a diferentes momentos en el tiempo, sería un gran aporte para tener una perspectiva más acabada de la acción de la política fiscal y de su evolución a lo largo del tiempo.

Como la distribución del ingreso "primaria" (previa a la intervención del Estado) está determinada por diversas herencias de la riqueza tangible y material y del capital humano, la persistencia de la desigualdad refleja la inexistencia de políticas capaces de modificar esta situación en la región. Por supuesto, y como lo ha enfatizado la CEPAL en su trilogía de la igualdad (CEPAL, 2010,2012 b y 2014b), es menester desplegar múltiples iniciativas para el cambio estructural con igualdad. Pero, sin duda, las políticas fiscales redistributivas han de contribuir en el futuro a cambiar este estigma regional. 


\section{Bibliografía}

Altimir, O. (1987), "Income distribution statistics in Latin America and their reliability", Review of Income and Wealth, vol. 33, $\mathrm{N}^{\circ}$ 2, New Haven, Asociación Internacional de Investigaciones sobre Rentas y Riquezas.

Barreix, A., M. Bes y J. Roca (2009), "Equidad fiscal en Centroamérica, Panamá y República Dominicana", Washington, D.C., Banco Interamericano de Desarrollo (BID)/EUROsociAL.

Barreix, A., J. Roca y L. Villela (2006), "La equidad fiscal en los países andinos", Washington, D.C., Banco Interamericano de Desarrollo (BID)/EURosociaL.

Bosch, M., A. Melguizo y C. Pagés (2013), Mejores pensiones, mejores trabajos: Hacia la cobertura universal en América Latina y el Caribe, Washington, D.C., Banco Interamericano de Desarrollo (BID).

CEPAL (Comisión Económica para América Latina y el Caribe) (2014a), "Panorama fiscal de América Latina y el Caribe: Hacia una mayor calidad de las finanzas públicas" (LC/L.3766), Santiago de Chile.

(2014b), Pactos para la igualdad: Hacia un futuro sostenible (LC/G.2586 (SES.35/3)), Santiago de Chile.

(2013a), "Panorama fiscal de América Latina y el Caribe: Reformas tributarias y renovación del pacto fiscal" (LC/L.3580), Santiago de Chile.

(2013b), Panorama Social de América Latina 2013 (LC/G.2580), Santiago de Chile. Publicación de las Naciones Unidas, $\mathrm{N}^{\circ}$ de venta: S.14.II.G.6

(2012a), "La medición de los ingresos en la encuesta CASEN 2011-R2", Santiago de Chile, agosto, versión preliminar.

(2012b), Cambio estructural para la igualdad: Una visión integrada del desarrollo (LC/G.2524 (SES.34/3)), Santiago de Chile.

(2012c), Panorama Social de América Latina 2011 (LC/ G.2514-P), Santiago de Chile. Publicación de las Naciones Unidas, $\mathrm{N}^{\circ}$ de venta: S.12.II.G.6.

(2010), La hora de la igualdad: Brechas por cerrar, caminos por abrir (LC/G.2432 (SES.33/3)), Santiago de Chile.

(2008), Panorama Social de América Latina 2007 (LC/ G.2351-P), Santiago de Chile. Publicación de las Naciones Unidas, $\mathrm{N}^{\circ}$ de venta: S.07.II.G.124.

Cetrángolo, O. y J.C. Gómez Sabaini (2007), "La tributación directa en América Latina y los desafíos a la imposición sobre la renta", serie Macroeconomía del Desarrollo, $\mathrm{N}^{\circ} 60$ (LC/G.2838-P), Santiago de Chile, Comisión Económica para América Latina y el Caribe (CEPAL). Publicación de las Naciones Unidas, $\mathrm{N}^{\circ}$ de venta: S.07.II.G.159.

Díaz de Sarralde, S., C. Garcimartín y J. Ruiz-Huerta (2010), "La paradoja de la progresividad en países de baja tributación: el impuesto a la renta en Guatemala", Revista de la CEPAL, $\mathrm{N}^{\circ} 102$ (LC/G.2468-P), Santiago de Chile.

Gómez Sabaini, J.C. y D. Morán (2013), "Política tributaria en América Latina: agenda para una segunda generación de reformas", serie Macroeconomía del Desarrollo, $\mathrm{N}^{\circ} 133$ (LC/L.3632), Santiago de Chile, Comisión Económica para América Latina y el Caribe (CEPAL).

Goñi, E., J. Lopéz y L. Servén (2011), "Fiscal redistribution and income inequality in Latin America", World Development, vol. 39, $\mathrm{N}^{\circ}$ 9, Amsterdam, Elsevier.

Higgins, S. y otros (2013), "Social spending, taxes and income redistribution in Paraguay", CEQ Working Paper, $\mathrm{N}^{\circ} 11$.

Jorratt, M. (2011), "Evaluando la equidad vertical y horizontal en el impuesto al valor agregado y el impuesto a la renta: El impacto de reformas tributarias potenciales. Los casos del Ecuador, Guatemala y el Paraguay", serie Macroeconomía del Desarrollo, $\mathrm{N}^{\circ} 113$ (LC/L.3347), Santiago de Chile, Comisión Económica para América Latina y el Caribe (CEPAL).

(2010), "Equidad fiscal en Chile: Un análisis de la incidencia distributiva de los impuestos y el gasto social", Equidad Fiscal en Brasil, Chile, Paraguay y Uruguay, Washington, D.C. Banco Interamericano de Desarrollo (BID).

Joumard, I., M. Pisu y D. Bloch (2012), "Less income inequality and more growth - Are they compatible? Part 3. Income redistribution via taxes and transfers across OECD countries", OECD Economics Department Working Papers, $\mathrm{N}^{\circ}$ 926, OECD Publishing.

Lustig, N., C. Pessino y J. Scott (2013), "The impact of taxes and social spending on inequality and poverty in Argentina, Bolivia, Brazil, Mexico, Peru and Uruguay: An overview", CEQ Working Paper, $\mathrm{N}^{\circ} 13$.

ocDE (Organización para la Cooperación y el Desarrollo Económicos) (2008), Growing Unequal? Income Distribution and Poverty in OECD Countries, París, OECD Publishing.

OCDE/CEPAL/CIAT (Organización para la Cooperación y el Desarrollo Económicos/Comisión Económica para América Latina y el Caribe/Centro Interamericano de Administraciones Tributarias) (2014), Estadísticas tributarias de América Latina, OECD Publishing.

Ter-Minassian, T. (2012), "More than revenue: Main challenges for taxation in Latin America and the Caribbean", Policy Brief, $\mathrm{N}^{\circ}$ IDB-PB-175, Washington, D.C, Banco Interamericano de Desarrollo (BID).

Urzúa, C.M. (ed.) (2012), Fiscal inclusive development: Microsimulation Models for Latin America, México, D.F., Instituto Tecnológico y de Estudios Superiores de Monterrey (ITESM). 